\title{
Advanced Interferometric SAR Techniques with TanDEM-X
}

\author{
Alberto Moreira, Fellow, IEEE, Gerhard Krieger, Member, IEEE, Hauke Fiedler, Irena Hajnsek, Member, IEEE, \\ Marwan Younis, Member, IEEE, Manfred Zink and Marian Werner \\ German Aerospace Center (DLR), Microwaves and Radar Institute \\ 82230 Oberpfaffenhofen, Germany \\ Phone: + 49815328 2305, e-mail: alberto.moreira@dlr.de
}

\begin{abstract}
TanDEM-X is an innovative mission with a TerraSAR- $X$ add-on satellite for high-resolution singlepass SAR interferometry. The TanDEM- $X$ mission has the primary objective of generating a consistent, global DEM with an unprecedented accuracy according to the HRTI-3 specifications ( $2 \mathrm{~m}$ height accuracy, $12 \mathrm{~m}$ posting). Beyond that, TanDEM-X provides a configurable SAR interferometric platform for demonstrating new SAR techniques and applications. The launch of TanDEM-X is planned for 2009. This paper gives a short overview of the TanDEM-X mission concept, summarizes the basic products and gives several examples of new interferometric techniques that will be demonstrated with TanDEM-X.
\end{abstract}

Index Terms - Synthetic Aperture Radar (SAR), Bistatic SAR, Advanced Interferometric Techniques

\section{INTRODUCTION}

The main goal of the TanDEM-X mission [1][2][3] is the generation of a world-wide, consistent, timely, and high-precision digital elevation model (DEM) according to the emerging HRTI-3 standard (cf. Table I) as the basis for a wide range of scientific research, as well as for operational, commercial DEM production.

Besides the primary goal of the TanDEM-X mission, several secondary mission objectives based on advanced interferometric SAR techniques have been defined which represent an important and innovative asset of the mission: moving target indication with a distributed fouraperture displaced phase centre system; measurement of ocean currents and detection of ice drift by four-phase center along-track interferometry; high resolution SAR imaging based on a baseline induced shift of the Doppler and range spectra (super-resolution); the derivation of vegetation parameters with multi-baseline polarimetric SAR interferometry; large baseline bistatic SAR imaging for improved scene classification, as well as regional very high resolution DEM generation based on spotlight and large baseline interferometry. In this last case it will be possible to measure terrain deformation with centimeter accuracy without suffering from temporal decorrelation as in the case of differential SAR interferometry.

TanDEM-X is being implemented in the framework of a Public-Private Partnership (PPP) between the German Aerospace Center (DLR) and EADS Astrium $\mathrm{GmbH}$.
Table I DEM Specification for HRTI Level-3 Standard

\begin{tabular}{|c|c|c|}
\hline $\begin{array}{c}\text { Requirement } \\
\text { Relative Vertical } \\
\text { Accuracy }\end{array}$ & $\begin{array}{c}\text { Specification } \\
90 \% \text { linear point-to-point } \\
\text { error }\end{array}$ & $\begin{array}{c}\text { HRTI-3 } \\
(\text { slope }<20 \%)\end{array}$ \\
\hline $\begin{array}{c}\text { Absolute Vertical } \\
\text { Accuracy }\end{array}$ & $90 \%$ linear error & $10 \mathrm{~m}$ \\
\hline $\begin{array}{c}\text { Horizontal } \\
\text { Accuracy }\end{array}$ & $90 \%$ circular error & $10 \mathrm{~m}$ \\
\hline Spatial Resolution & independent pixels & $\begin{array}{c}12 \mathrm{~m} \\
(1 \mathrm{arc} \mathrm{sec})\end{array}$ \\
\hline
\end{tabular}

\section{MISSION CONCEPT}

The TanDEM-X mission concept is based on an extension of the TerraSAR-X mission [4][5][6] by a second TerraSAR-X like satellite. Both satellites will fly in close formation and will be operated as a flexible single-pass SAR interferometer where the baseline can be selected according to the specific needs of the application. This enables the acquisition of highly accurate cross-track and along-track interferograms without the inherent accuracy limitations imposed by repeat-pass interferometry due to temporal decorrelation and atmospheric disturbances. A prolongation of the nominal mission overlap of 3 years is possible by means of an extension of TerraSAR-X operation which is compatible with both satellites consumables and resources.

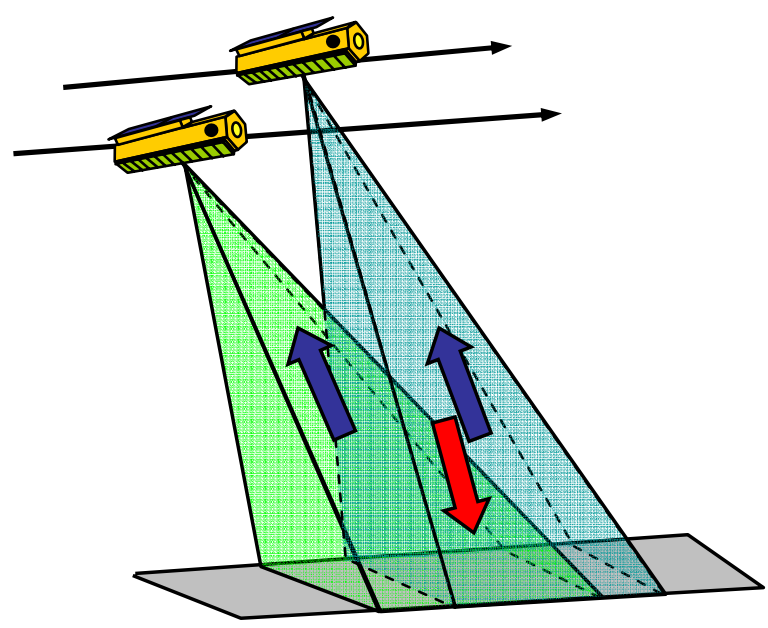

Figure 1 Bistatic interferometric SAR operation for TanDEM-X 
Interferometric data acquisition can be performed in the pursuit monostatic mode where both satellites are operated independently; the bistatic mode where one satellite serves as a transmitter and both satellites record the scattered signal simultaneously (cf. Figure 1); and the alternating bistatic mode where the transmitter changes from pulse to pulse.

Current baseline for operational DEM generation is the bistatic mode which minimizes temporal decorrelation and makes efficient use of the transmit power. The alternating bistatic mode can be used for phase synchronization, system calibration, and to acquire interferograms with different phase-to-height sensitivities, but the simultaneously acquired monostatic interferogram has a higher susceptibility to ambiguities especially at high incident angles [7]. Monostatic data takes are planned during the commissioning phase and at the end of the mission where the satellite formation is flown with a sufficient along-track separation between the satellites to avoid potential RF interferences.

The TanDEM-X operational scenario requires a coordinated operation of two satellites flying in close formation. Several options have been investigated and the HELIX satellite formation has finally been selected as shown in Figure 2. This formation combines an outof-plane orbital displacement by different ascending nodes with a radial (vertical) separation by different eccentricity vectors resulting in a helix like relative movement of the satellites along the orbit. Since there exists no crossing of the satellite orbits, it is now possible to arbitrarily shift the satellites along their orbits, e.g. to adjust very small along-track baselines at predefined latitudes and to allow safe spacecraft operation without autonomous control. The HELIX formation enables a complete coverage of the Earth with a stable height of ambiguity by using a small number of formations [8][9][10][11]. Baseline fine tuning can be achieved by taking advantage of the natural rotation of the eccentricity vectors due to secular disturbances and fixating the eccentricity vectors at different relative phasings.

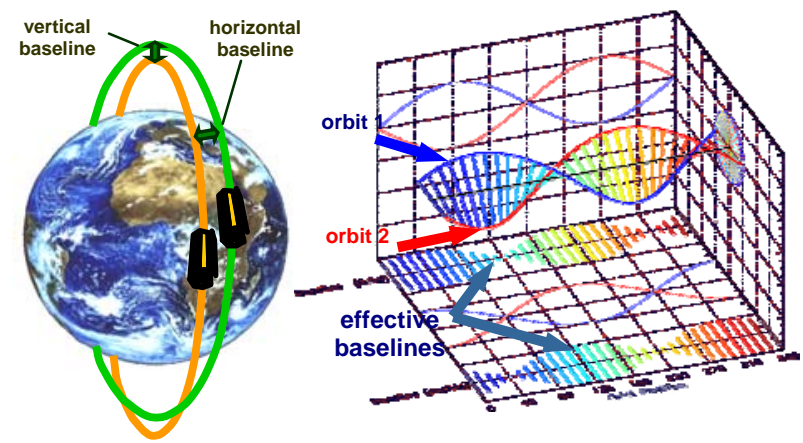

Figure 2 HELIX orbit for the TerraSAR-X and TanDEM-X satellites.
An appropriate reference scenario has been derived which enables two complete coverages of the Earth with baselines corresponding to a height of ambiguity of ca. $25-35 \mathrm{~m}$ and $35-45 \mathrm{~m}$ within ca. 2 years of bi-static data acquisition in stripmap mode [8]. This increases the robustness and redundancy for interferometric processing and allows the use of multi-baseline phase unwrapping techniques for reliable DEM generation. For mountainous areas, which correspond to ca. $10 \%$ of the Earth surface, additional data acquisitions with different baselines and viewing geometries will be carried out.

\section{PRODUCt DEFINITION}

Two basic product classes are defined for TanDEM$\mathrm{X}$ in cooperation with both the scientific and the commercial users [12][13].

\section{A. Digital Elevation Models (DEM)}

This product class comprises all DEM data products. The DEM class is divided into two sub-classes: standard and customized DEMs. The standard DEMs will be available globally after all interferometric data from the TanDEM-X mission are processed. The specification for the standard DEM is aligned with the emerging HRTI-3 standard shown in Table I, but some modifications have been made to take into account the different user requirements. The major modification concerns the different trade-offs between horizontal and vertical resolution. Other modifications concern e.g. the vertical datum where it was decided to use the WGS 84 ellipsoid instead of the Mean Sea Level. Standard DEMs will be available at the resolutions shown in Table II.

Table II TanDEM-X DEM Specification

\begin{tabular}{|c|c|c|c|c|}
\hline & $\begin{array}{c}\text { DSM } \\
50\end{array}$ & $\begin{array}{c}\text { DSM } \\
25\end{array}$ & HRTI-3 & HSR \\
\hline Post Spacing & $50 \mathrm{~m}$ & $25 \mathrm{~m}$ & $12 \mathrm{~m}$ & $6 \mathrm{~m}$ \\
\hline $\begin{array}{c}\text { Relative Height } \\
\text { Accuracy }\end{array}$ & $0.5 \mathrm{~m}$ & $1 \mathrm{~m}$ & $2 \mathrm{~m}$ & $4 \mathrm{~m}$ \\
\hline
\end{tabular}

It is assumed that all these DEM products can be derived from one and the same TanDEM-X SAR data acquisition by applying different multi-looking windows during the interferometric processing.

Moreover, TanDEM-X will be able to produce Customized DEMs on a local basis. Customized DEM acquisition takes into account specific user demands regarding imaging geometry, DEM accuracy, and acquisition time. The performance goal for improved DEM generation is 0.8 meter relative height accuracy for an independent post spacing of 6 meter, as required by the emerging HRTI-4 standard. 


\section{B. Radar Data Products (RDP)}

This product class comprises all TanDEM-X data products which are not covered by the DEM class. Examples are SAR data products for along-track interferometry, polarimetric SAR interferometry, fourphase centre moving target indication, bistatic SAR imaging, and digital beamforming. The user customer has to provide specific data acquisition parameters like e.g. interferometric baselines and imaging geometry, SAR operation modes, instrument settings, and so on. TanDEM-X will then acquire the desired SAR data during the available time slots, allowing the demonstration of advanced interferometric techniques. The following data will be available:

- $\quad$ SAR raw data (only on special request)

- auxiliary data e.g. baseline, precise orbit, calibration data, system errors, accuracy

- $\quad$ single look complex (SLC) SAR images

- $\quad$ SLC quality flags

- SAR interferograms

Each interested scientist/customer will have the possibility to develop new interferometric techniques and algorithms from the Radar Data Products offered by TanDEM-X.

\section{NEW INTERFEROMETRIC TECHNIQUES}

The TanDEM-X mission will provide the remote sensing scientific community with a unique data set to exploit the capability of new advanced interferometric SAR techniques and to apply these innovative techniques for enhanced parameter retrieval.

\section{A. Four-Phase Center Along-Track Interferometry}

TanDEM-X is predestined for along-track interferometry (ATI), which compares the phase of two complex SAR images acquired in identical geometries but separated by a short time interval. This technique is well suited for monitoring dynamic processes on the Earth's surface. The along-track displacement between the two satellites can be adjusted from almost zero to several kilometers. By this, it becomes possible to adapt the ATI sensitivity of TanDEM-X to a wide range of radial velocities. The HELIX formation enables even a minimization of the across-track component for a given latitude and incident angle. Along-track interferometry can furthermore be performed by the so-called dual-receive antenna mode [14] in each of the two tandem satellites, which provides additional along-track baselines of $2.4 \mathrm{~m}$. The combination of short and long baseline ATI data acquisitions can be used to improve both the detection and localisation of moving objects and to resolve phase ambiguities from high-velocity scatterers. TanDEM-X provides hence a capable along-track SAR interferometer with four phase centers. Potential applications are Ground Moving Target Indication (GMTI), the measurement of ocean currents, and the monitoring of sea ice drift.

\section{B. Very Large Baseline Cross-Track Interferometry}

Very Large Baseline Interferometry takes advantage of the large bandwidth of the TerraSAR-X and TanDEM-X satellites to significantly improve the height accuracy for local areas by combining multiple interferograms with different baseline lengths. This can e.g. be used to acquire DEMs with HRTI-4 like quality on a local or even regional scale. A temporal comparison of multiple large baseline interferograms (either phase or coherence) provides furthermore a very sensitive measurable for vertical scene and structure changes (Figure 3). Potential applications are a detection of the grounding line which separates the shelf from the inland ice, monitoring of vegetation growth, measurement of snow accumulation or the detection of anthropogenic changes of the environment, e.g. due to deforestation.
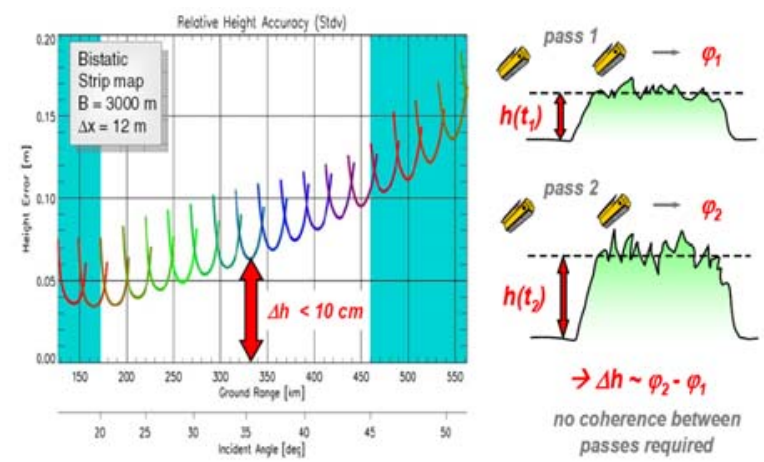

Figure 3 Performance example for double differential SAR interferometry with TanDEM-X (cross-track baseline $=3000 \mathrm{~m}$, posting $=12 \mathrm{~m}$ ). A relative height accuracy (standard deviation) better than $10 \mathrm{~cm}$ is achieved

\section{Polarimetric SAR Interferometry}

Polarimetric SAR interferometry combines interferometric with polarimetric measurements to gain additional information from volume scatterers [15][16]. This allows e.g. for the extraction of important biophysical parameters like vegetation density and vegetation height. Fully polarimetric operation uses the split antenna and is susceptible to ambiguities. This can be avoided by reducing the processed azimuth bandwidth and/or by limiting the swath width. Fig. 4 illustrates the achievable performance of a simulated scenario for TanDEM-X. This analysis is based on the Random Volume over Ground (RVoG) model assuming a vegetation layer with a height of $0.6 \mathrm{~m}$ and an extinction coefficient of $10 \mathrm{~dB} / \mathrm{m}$ [17]. The dashed line indicates the height variation of the interferometric phase centre with different polarisations (corresponding to a variation of $\mu$ on the abscissa). The green tube shows the height errors 
due to volume decorrelation for an effective baseline of $5 \mathrm{~km}$ and an independent post-spacing of $30 \mathrm{~m} \times 30 \mathrm{~m}$. The blue tube shows additional errors due to the limited system accuracy and the red tube indicates potential errors in case of temporal decorrelation $\gamma_{\text {Temp }}$ caused by a possible along-track separation between the two satellites (here: $\gamma_{\text {Temp }}=0.7$ ). The performance analysis predicts a sufficient phase centre separation to enable a successful retrieval of important vegetation parameters like volume height and extinction (Figure 4). TanDEM$\mathrm{X}$ will be the first mission to demonstrate this technique in a single-pass data acquisition mode.

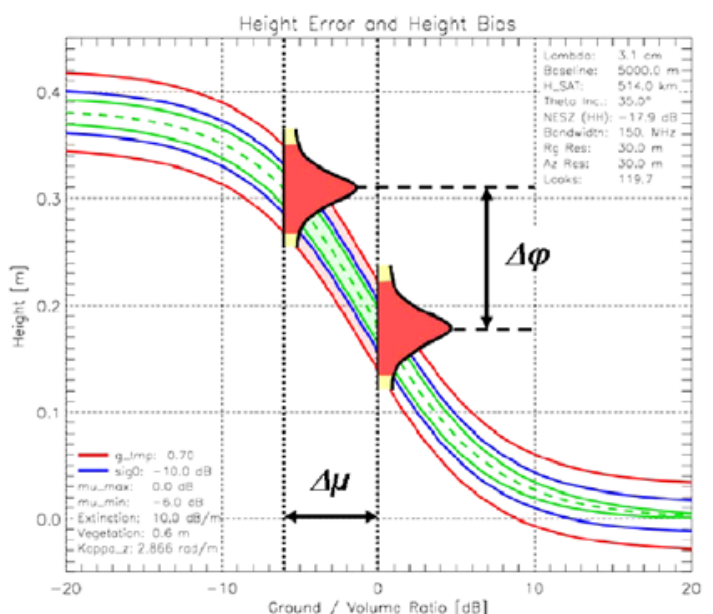

Figure 4 Vertical separation of interferometric phase centers in TanDEM-X as a function of the ground-to-volume scattering ratio. The vegetation height is $0.6 \mathrm{~m}$, the ground-to-volume ratio varies from $-6 \mathrm{~dB}$ to $0 \mathrm{~dB}$ and the extinction is $10 \mathrm{~dB} / \mathrm{m}$.

\section{Bi-Static SAR Imaging}

Bistatic SAR imaging provides additional observables for the extraction of important scene and target parameters [18][19]. TanDEM-X allows for the simultaneous acquisition of bistatic and monostatic images in a single data take to obtain a highly informative set of multi-angle observations. A quantitative evaluation of the bistatic radar cross-section (RCS) and a comparison with its monostatic equivalents facilitates the detection and recognition of targets. The segmentation and classification in radar images is expected to be substantially improved by comparing the spatial statistics of mono- and bistatic scattering coefficients. This is also supported by the joint airborne bistatic radar experiments performed by DLR and ONERA, which revealed significant changes of the scattering behaviour for both artificial and natural targets even in case of rather small bistatic angles [20]. A joint evaluation of mono- and bistatic SAR images could furthermore be used to isolate different scattering mechanisms, like e.g. a distinction between highly directive dihedral returns from more isotropic volume scattering. Bistatic SAR imaging has moreover potential for the retrieval of sea state parameters, the estimation of surface roughness and terrain slope, as well as stereogrammetric, meteorological and atmospheric applications. Innovative processing algorithms will be required to exploit all these capabilities. The bistatic data acquired with TanDEM-X will hence provide a unique data source to improve our understanding of bistatic imaging and its exploitation for future remote sensing applications. Data takes with large bistatic angles are planned at the beginning and at the end of the TanDEM$\mathrm{X}$ mission where the satellites are separated from each other by several tenths of kilometers.

\section{Digital Beamforming and Super Resolution}

Digital Beamforming combines the RF signals from a set of small non-directional antennas to simulate a large directional antenna. Due to the split antennas and dual receiver channels of TSX and TDX, four-phase centers can be obtained in a tandem mode. An appropriate combination of the multiple $\mathrm{Rx}$ signals enables then an efficient suppression of azimuth ambiguities [21][22][23][24]. By this, it is possible to demonstrate the capabilities of high resolution wide swath SAR imaging. This technique could also be of interest for advanced interferometric SAR modes like the alternating bistatic mode where it allows for a reduction of the PRF, thereby resolving potential timing and ambiguity conflicts. TanDEM-X will be the first configuration that demonstrates this highly innovative technique from space.

Another promising technique is super resolution. This technique exploits the fact that the signals received by the two satellites have different aspect angles for each scattering point on the ground. In consequence, the two ground range and/or azimuth spectra are shifted relative to each other. A coherent combination of the signals yields then a wider spectrum which corresponds to an improved spatial resolution. This technique requires a cross-track and/or along-track separation in the order of 5 to $10 \mathrm{~km}$. Such baselines will be available in later mission phases after the standard DEM data acquisition has been completed.

\section{CONCLUSIONS}

TanDEM-X is a highly innovative bistatic singlepass SAR interferometer which allows for the acquisition of unique remote sensing data products. The achievable height accuracy for global DEM generation with TanDEM-X is mainly limited by the height of ambiguity that can finally be processed during phase unwrapping. The standard HRTI-3 DEM is a reasonable compromise between performance, processing, and data acquisition effort. A mission scenario has been developed which enables the acquisition of a global HRTI-3 DEM within less than three years. This concept includes several data 
includes several data takes with different baselines, different incident angles, and data takes from ascending and descending orbits to deal with difficult terrain like mountains, valleys, tall vegetation, etc. The TanDEM-X mission concept allocates also sufficient acquisition time and satellite resources to secondary mission goals like along-track interferometry or the demonstration of new bistatic radar techniques.

In 2006, the TanDEM-X mission has been approved for realization by means of a public private partnership between the German Aerospace Center (DLR) and EADS Astrium GmbH. The launch of the TanDEM-X satellite is planned for spring 2009 which ensures at least three years of joint operation with the TerraSAR-X satellite. Current work includes the preparation of a detailed data acquisition plan which has also to take into account potential conflicts between the TerraSAR-X and the TanDEM-X mission, the development and analysis of a calibration concept, the design of a multibaseline InSAR processor, the compilation of a science plan as well as performance investigations for the other innovative TanDEM-X imaging modes.

\section{REFERENCES}

[1] A. Moreira, G. Krieger, I. Hajnsek, M. Werner, D. Hounam, S. Riegger, E. Settelmeyer, "TanDEM-X: A TerraSAR-X Add-On Satellite for Single-Pass SAR Interferometry", IGARSS 2004, Anchorage, USA.

[2] G. Krieger, A. Moreira, H. Fiedler, I. Hajnsek, M. Werner, M. Younis, M. Zink, "TanDEM-X: A Satellite Formation for High Resolution SAR Interferometry," IEEE Transactions on Geoscience and Remote Sensing, vol. 45, No. 11, Nov. 2007.

[3] TanDEM-X DLR WebPage. http://www.dlr.de/hr/tdmx

[4] R. Werninghaus, W. Balzer, St. Buckreuss, J. Mittermayer, P. Mühlbauer, "The TerraSAR-X Mission”, EUSAR 2004, Ulm, Germany.

[5] M. Stangl, R. Werninghaus, B. Schweizer, C. Fischer, M. Brandfass, J. Mittermayer, and H. Breit, "TerraSAR-X Technologies and First Results," IEE Proceedings - Radar, Sonar and Navigation, vol. 153, pp. 86-95, 2006.

[6] S. Buckreuss, R. Werninghaus, W. Pitz: TerraSAR-X Mission Status. IRS 2007, Cologne, Germany.

[7] G. Krieger, "TanDEM-X Phase A Study: Mission Analysis and System Performance", TSXT-RD-DLR-1100, June 2005.

[8] H. Fiedler, "TanDEM-X Phase A Study: Formation and Coverage Concept", DLR Technical Note, June 2005.

[9] A. Moreira, G. Krieger, J. Mittermayer, "Satellite Configuration for Interferometric and/or Tomographic Remote Sensing by Means of Synthetic Aperture Radar (SAR)," US Patent 6,677,884, July 2002.

[10] H. Fiedler, G. Krieger, "Close Formation of Passive Receiving Micro-satellites," $18^{\text {th }}$ Int. Symp. Space Flight Dynamics, Germany, 2004.

[11] S. D'Amico, O. Montenbruck, C. Arbinger, H. Fiedler, "Formation Flying Concept for Close Remote Sensing
Satellites," 15th AAS/AIAA Space Flight Mechanics Conference 2005, Colorado, USA, 2005.

[12] I. Hajnsek and M. Weber: "TanDEM-X User Requirements Document", Technical Note TDX-RD-DLR-1201, Issue 1.2, 20 June 2005.

[13] I. Hajnsek and A. Moreira, "TanDEM-X: Mission and Science Exploration," in Proc. EUSAR, Dresden, Germany, May 2006.

[14] J. Mittermayer and H. Runge, "Conceptual Studies for Exploiting the TerraSAR-X Dual Receive Antenna," in Proc. IGARSS, Toulouse, France, 2003.

[15] S.R. Cloude and K.P. Papathanassiou, "Polarimetric SAR interferometry," IEEE Transactions on Geoscience and Remote Sensing, vol. 36, pp. 1551-1565, 1998.

[16] K.P. Papathanassiou and S. R. Cloude, "Single-baseline polarimetric SAR interferometry," IEEE Transactions on Geoscience and Remote Sensing, vol. 39, pp. 2352-2363, 2001.

[17] G. Krieger, K. Papathanassiou, S. Cloude, "Spaceborne Polarimetric SAR Interferometry: Performance Analysis and Mission Concepts," EURASIP Journal on Applied Signal Processing, vol. 20, pp. 3272-3292, 2005.

[18] G. Krieger and A. Moreira, "Spaceborne Bi- and Multistatic SAR: Potential and Challenges," IEE Proceedings - Radar, Sonar and Navigation, vol. 153, pp. 184-198, 2006.

[19] A. Moccia, N. Chiacchio, and A. Capone, "Spaceborne bistatic synthetic aperture radar for remote sensing applications," International Journal of Remote Sensing, vol. 21, pp. 3395-3414, 2000.

[20] P. Dubois-Fernandez, H. Cantalloube, B. Vaizan, G. Krieger, R. Horn, M. Wendler, and V. Giroux, "ONERADLR bistatic SAR campaign: Planning, data acquisition, and first analysis of bistatic scattering behavior of natural and urban targets," IEE Proceedings - Radar, Sonar and Navigation, vol. 153, pp. 214-223, 2006.

[21] M. Suess, B. Grafmueller, and R. Zahn, "A novel high resolution, wide swath SAR system," in Proc. IEEE Geoscience and Remote Sensing Symposium, Sydney, Australia, pp. 1013-1015, 2001.

[22] M. Younis, C. Fischer, and W. Wiesbeck, "Digital beamforming in SAR systems," IEEE Transactions on Geoscience and Remote Sensing, vol. 41, pp. 1735-1739, 2003.

[23] G. Krieger, N. Gebert, and A. Moreira, "Unambiguous SAR signal reconstruction from nonuniform displaced phase center sampling," IEEE Geoscience and Remote Sensing Letters, vol. 1, pp. 260-264, 2004.

[24] G. Krieger, N. Gebert, A. Moreira, "Multidimensional Waveform Encoding: A New Digital Beamforming Technique for Synthetic Aperture Radar Remote Sensing," IEEE Transactions on Geoscience and Remote Sensing, vol. 46, pp. 31-46, 2008. 